DR MARTIN SCHULTZ (Orcid ID : 0000-0003-3458-1811)

Article type : Original Article

\title{
Masked hypertension and submaximal exercise blood pressure among adolescents from the Avon Longitudinal Study of Parents and Children (ALSPAC).
}

\author{
Zhengzheng Huang, ${ }^{1}$ James E. Sharman, ${ }^{1}$ Ricardo Fonseca, ${ }^{1}$ Chloe Park, ${ }^{2,3}$ Nish \\ Chaturvedi, ${ }^{2,3}$ George Davey Smith, ${ }^{4}$ Laura D Howe, ${ }^{4}$ Deborah A Lawlor, ${ }^{4}$ Alun D. \\ Hughes, ${ }^{2,3}$ and Martin G. Schultz. ${ }^{1}$
}

1) Menzies Institute for Medical Research, University of Tasmania, Hobart, Australia

2) Department of Population Science \& Experimental Medicine, Institute of Cardiovascular Science, University College London, London, UK

3) MRC Unit for Lifelong Health and Ageing at UCL, University College London, London, UK.

4) MRC Integrative Epidemiology Unit, University of Bristol, Bristol, UK

Running Head: Exercise blood pressure and masked hypertension

\section{Corresponding author:}

Dr Martin G. Schultz

Menzies Institute for Medical Research, College of Health and Medicine, University of Tasmania, Hobart, 7000, Australia

Telephone: +61(0) 362264264

Fax: +61 (0)3 62267704

Email: Martin.Schultz@utas.edu.au

This article has been accepted for publication and undergone full peer review but has not been through the copyediting, typesetting, pagination and proofreading process, which may lead to differences between this version and the Version of Record. Please cite this article as doi: $10.1111 / \mathrm{sms} .13525$

This article is protected by copyright. All rights reserved. 


\begin{abstract}
Purpose. Masked hypertension is associated with increased cardiovascular risk but is undetectable by clinic blood pressure (BP). Elevated systolic BP responses to submaximal exercise reveal the presence of masked hypertension in adults, but it is unknown whether this is the case during adolescence. We aimed to determine if exercise BP was raised in adolescents with masked hypertension, and its association with cardiovascular risk markers. Methods. 657 adolescents (aged 17.7 \pm 0.3 years; $41.9 \%$ male) from the Avon longitudinal study of parents and children (ALSPAC) completed a step-exercise test with pre-, post- and recovery-exercise BP, clinic BP and 24-hour ambulatory BP. Masked hypertension was defined as clinic BP $<140 / 90 \mathrm{mmHg}$ and 24-hour ambulatory $\mathrm{BP} \geq 130 / 80 \mathrm{mmHg}$. Assessment of left-ventricular (LV) mass index and carotid-femoral pulse wave velocity (aortic PWV) was also undertaken. Thresholds of clinic, pre-, post- and recovery-exercise systolic BP were explored from ROC analysis to identify masked hypertension. Results. Fifty participants (7.8\%) were classified with masked hypertension. Clinic, pre-, post- and recovery-exercise systolic BP were associated with masked hypertension (AUC $\geq 0.69$ for all respectively), with the clinic systolic BP threshold of $115 \mathrm{mmHg}$ having high sensitivity and specificity and exercise BP thresholds of 126, 150 and $130 \mathrm{mmHg}$ respectively having high specificity and negative predictive value (individually or when combined) for ruling out the presence of masked hypertension. Additionally, these exercise systolic BP above the thresholds was associated with greater left-ventricular mass index and aortic PWV. Conclusions. Submaximal exercise systolic BP is associated with masked hypertension and adverse cardiovascular structure in adolescents. Exercise BP may be useful in addition to clinic BP for screening of high BP and cardiovascular risk in adolescents.
\end{abstract}

This article is protected by copyright. All rights reserved. 
Key words. ALSPAC; exercise test; masked hypertension; vascular stiffness; body composition; adolescent

\section{Introduction}

Raised blood pressure (BP) is a significant risk factor for cardiovascular morbidity and mortality. ${ }^{1}$ In practice, BP is most commonly measured in the clinic, seated at rest. However, this approach is limited with respect to establishing habitual BP. Indeed, while BP may appear within normal limits in the clinic, out-of-clinic BP may be raised, a condition termed masked hypertension. ${ }^{2,3}$ Masked hypertension is associated with a three-fold risk of sustained hypertension and cardiovascular mortality compared to that of normal BP in adults. ${ }^{4-7}$ When diagnosed in childhood or adolescence, individuals are at increased risk of adverse cardiovascular outcomes in later life (e.g. incident hypertension and left ventricular hypertrophy). ${ }^{5,8}$ Thus, the early detection of masked hypertension is important for the prevention of cardiovascular disease.

24-hour ambulatory BP monitoring or home BP monitoring combined with clinic BP assessment are required to detect masked hypertension. ${ }^{9,}{ }^{10}$ However, for individuals who have normal clinic BP without any other clinical information which indicates target organ damage or chronic disease, it is unlikely that they would be referred to do ambulatory BP monitoring, and thus a diagnosis of hypertension could be missed. Previous studies in small, selected adult populations have shown that an exaggerated systolic BP response to submaximal (light-to-moderate intensity) exercise testing can reveal underlying or masked hypertension. ${ }^{9,}{ }^{11}$ It does, however, remain unknown if submaximal exercise BP is useful in revealing or ruling out the presence of masked hypertension in adolescents, which was the primary aim of this study. We also aimed to determine threshold values of submaximal 
exercise BP associated with masked hypertension, and markers of cardiovascular risk, including left-ventricular mass index and aortic stiffness.

\section{Methodology}

Participants. Data from the Avon Longitudinal Study of Parents and Children (ALSPAC), a large ongoing population-based birth cohort study in the UK, were used. Information on the study cohort has been reported previously, ${ }^{12,13}$ and details of all data available fully searchable via an online data dictionary and variable search tool (http://www.bristol.ac.uk/alspac/researchers/our-data/). The total sample size for analysis using any data collected after the age of seven is 15,247 pregnancies, resulting in 15,458 fetuses. Of this total sample, 14,775 were live births and 14,701 were alive at 1 year of age. 9486 participants did not attend the 17-year follow-up clinics. Of the 5215 eligible participants from this 17-year subset, 4558 participants were excluded if missing demographic data (sex), pre-exercise BP, post-exercise BP, recovery-exercise BP and 24hour ambulatory BP as indicated in figure 1. The sample population of the current study included 657 adolescents who were part of the 17-year follow-up. This sample of adolescents completed a submaximal exercise step-test with pre-exercise, post-exercise and recoveryexercise BP measurement, clinic and 24-hour ambulatory BP measurements. Markers of cardiovascular structure including left-ventricular mass index (LVMI) and carotid-femoral (aortic) pulse wave velocity (PWV) were collected on further sub-samples from the final 657 ( $n=567$ and 541 respectively). A flow chart of participation is given in figure 1. Ethical approval for the study was obtained from the ALSPAC Ethics and Law Committee and the Local Research Ethics Committees. Each participant provided written consent for participation. 
Exercise testing and BP. Participants completed an exercise step-test (modified Tecumseh). ${ }^{14}$ This involved stepping onto and off a step at a height of $20 \mathrm{~cm}$, at a rate of 23 steps per minute for three minutes. A metronome was used to set the tempo of steps. Systolic $\mathrm{BP}$, diastolic $\mathrm{BP}$ and pulse rate were measured using a validated automatic monitor (Omron 705 IT, Omron Electronic Components, Europe BV) with an appropriate sized cuff fitted to the upper arm. A single BP measure was obtained immediately prior to the beginning of the step-test, while the participant was standing with their arm naturally at their side (pre-exercise BP). Participants continued to wear the BP cuff during the step-test and a further singlemeasure was recorded at the end of stepping within the first 30 seconds (post-exercise BP). A third single-measure was recorded starting at three minutes after completion of the test (recovery-exercise BP). The change in systolic BP from pre- to post-exercise (pre-post systolic BP change) was calculated as post-exercise BP less pre-exercise BP, whilst the change in BP from post-exercise to recovery (post-recovery systolic BP change) was calculated as post-exercise BP less recovery-exercise BP.

Clinic BP. Assessment of clinic BP was undertaken before the exercise test, on the same day. Arm circumference was measured and an appropriate sized cuff placed onto the upper arm. Measurement was performed using the same automated device as used for exercise BP, in the seated position after five minutes rest. Three readings were taken and the average of the final two was used for analysis. Clinic BP was classified as raised based on adult hypertension thresholds (systolic and/or diastolic BP $\geq 140 / 90 \mathrm{mmHg})^{2}$ in accordance with European adolescent hypertension guidelines for individuals older than 16 years of age. ${ }^{15}$

This article is protected by copyright. All rights reserved. 
Out-of-clinic BP. Ambulatory BP was assessed using an automated monitor (Spacelabs 90217, Spacelabs Healthcare, Issaquah, Washington, United States). Participants were fitted with the device upon completion of the exercise test and were required to wear it for the subsequent 24 hours. Measures of systolic and diastolic BP were recorded every 30 minutes during the day and hourly during overnight. Participants were instructed to not remove the device during sleep. Daytime and night-time were defined by the participant. ${ }^{16}$ Whilst the expected maximum number of total readings per participant therefore varied on the duration of the night-time period, it was expected in the range of $36-42$ total (24 - 27 valid) and daytime $24-36$ total (16 - 23 valid); night-time $6-12$ total (4 - 8 valid). Whilst the differences in number of valid readings would not likely impact results, ${ }^{17}$ expected numbers correspond reasonably with the daytime limits suggested by $\mathrm{O}^{\prime} B$ rien et $\mathrm{al}^{18}$ and the nighttime limits used by Mezick et al. ${ }^{19}$ The average of daytime, night-time and 24-hour BP (calculated as the average of all valid readings during the defined daytime, night-time and 24hour periods) was used for analysis. There is currently no consensus on ambulatory hypertension thresholds in adolescents. For consistency with clinic BP thresholds, we therefore defined raised ambulatory BP based on adult ambulatory hypertension thresholds as 24-hour systolic and/or diastolic $\mathrm{BP} \geq 130 / 80 \mathrm{mmHg} .{ }^{2}$ Normal ambulatory BP was defined as 24-hour BP $<130 / 80$ mmHg. Normal BP was defined as normal clinic BP and normal 24hour ambulatory. Masked hypertension was defined as normal clinic BP but raised 24-hour ambulatory BP. White coat hypertension was defined as raised clinic BP and normal 24-hour ambulatory BP. Hypertension was defined as raised clinic BP and raised 24-hour ambulatory BP. BP load (percentage time during which BP readings exceed hypertension threshold over 24 hours) was calculated as the percentage number and duration of readings exceeding the following limits; daytime 140/90 mmHg; Night time 120/80 mmHg. Nocturnal dipping 
(percent day-night difference) was determined for systolic and diastolic BP as (mean daytime $\mathrm{BP}$ - mean night- time BP)/mean daytime BP.

Anthropometrics and blood biochemistry. Height was estimated to the nearest $0.1 \mathrm{~cm}$ with a Harpenden Stadiometer. Body weight was measured to the nearest $0.1 \mathrm{~kg}$ using a Tanita TBF 305 scale. Body mass index was calculated as weight $(\mathrm{kg}) /$ height (meters) ${ }^{2}$. Blood samples were collected following overnight fast for those assessed in the morning or a minimum 6-hours for those assessed in the afternoon. Biochemistry analysis of glucose and cholesterol was performed following locally established procedures.

Cardiovascular assessments. A comprehensive cardiac echocardiogram was undertaken to determine cardiac structure using a HDI 5000 (Phillips Healthcare, North Andover, Massachusetts, USA) ultrasound with integrated P4-2 phased array ultrasound transducer. Left ventricular (LV) mass was calculated according to the guidelines of American Society of Echocardiography and indexed to height ${ }^{2.7} \cdot{ }^{20}$ Measurement of large artery (aortic) stiffness was undertaken by ECG-gated carotid-femoral PWV using the Vicorder device (Version 5.1; Skidmore Medical Ltd) and following consensus guidelines. ${ }^{21}$

Statistical analysis. All data were analysed using IBM SPSS Statistics, version 24.0. Numerical and visual outputs including the Shapiro-Wilk test and normal Q-Q plots were assessed to check normality of distributions. Differences in continuous variables were assessed by t-tests and one-way analysis of variance (ANOVA), and categorical variables by chi-square. Multiple linear regression was performed to adjust for potential confounders of 
associations. Receiver operator characteristic (ROC) curve analyses were performed to detect optimal post-exercise and recovery-exercise systolic BP threshold values that associated with the presence of masked hypertension. The area under the ROC curve (AUC) was quantified to determine the overall 'accuracy' of clinic, pre-exercise, post-exercise and recoveryexercise systolic BP for detecting masked hypertension. Thresholds of all BP's were created based on either 1) Youden's criterion as the maximised sum of sensitivity plus specificity or 2) the minimal difference between sensitivity and specificity. In addition, pre-exercise, postexercise and recovery-exercise BP thresholds were combined in different ways (i.e. by combining post- and recovery-exercise BP thresholds, or pre-, post- and recovery-exercise BP thresholds) to assess whether this improved the identification of masked hypertension. Sensitivity (the true positive rate), specificity (the true negative rate), positive predictive value (PPV), negative predictive value (NPV), positive likelihood ratio $(\mathrm{LR}+)$ and negative likelihood ratio (LR-) were determined for each threshold. Log-binominal models were used to directly estimate prevalence ratios (PR) as per methods previously outlined, ${ }^{22-24}$ and to determine the association of the post-exercise systolic BP or recovery-exercise systolic BP (adjusting for age, sex, BMI and clinic (resting) systolic BP) with the presence of masked hypertension.

\section{Results}

$588(89.5 \%)$ participants were classified with normal BP and $50(7.8 \%)$ with masked hypertension. Some participants were classified with white coat hypertension $(11,1.7 \%)$, or hypertension $(8,1.2 \%)$ but were not included in further analyses. One participant was pregnant; three self-reported a diagnosis of diabetes and seven participants reported hypertension. Sex distribution and height were similar among those classified with masked 
hypertension and those with normal BP. Those classified with masked hypertension had greater BMI, weight, higher total cholesterol and triglyceride levels compared to those with normal BP (table 1).

Participants classified with masked hypertension had higher clinic systolic and diastolic BP (table 2a), higher daytime, night time and 24-hour average ambulatory systolic and diastolic $\mathrm{BP}$ as well as systolic and diastolic BP load compared to those classified with normal BP (table 2b). Pre-exercise, post-exercise and recovery-exercise systolic and diastolic BP were higher in those classified with masked hypertension compared with those classified with normal BP (table 2c). Heart rate was similar between the two groups before, after exercise or during the recovery period. There were also no differences in systolic BP change pre-post and post-recovery between the two groups.

All systolic BP measures (clinic, 24-hour, pre-, post-, and recovery exercise BP) were associated with each other (see supplementary table 1). Clinic, pre-exercise systolic BP, postexercise systolic BP and recovery-exercise systolic BP was associated with masked hypertension $(\mathrm{AUC}=0.80,95 \% \mathrm{CI}: 0.75-0.86, \mathrm{AUC}=0.73,95 \% \mathrm{CI}: 0.65-0.81, \mathrm{AUC}=0.69$, 95\% CI: 0.61-0.76, AUC $=0.74,95 \%$ CI: 0.67-0.81). Clinic BP had a greater AUC vs. preexercise systolic BP $(P<0.05)$, post-exercise systolic BP $(P<0.05)$ and recovery-exercise systolic BP $(P=0.06)$. Pre-exercise BP had a similar AUC vs. post-exercise systolic BP $(P=0.19)$ and recovery-exercise BP vs. post-exercise systolic BP $(P=0.10)$. A pre-exercise systolic BP threshold of $126 \mathrm{mmHg}$, a post-exercise systolic BP threshold of $150 \mathrm{mmHg}$ and a recovery-exercise systolic $\mathrm{BP}$ threshold of $130 \mathrm{mmHg}$ were identified as the optimal thresholds (Youden's index) from respective ROC analyses. Each threshold showed only modest sensitivity, but greater specificity (for ruling out) masked hypertension. PPV was low, but NPV high for each threshold (table 3). Similarly, the LR+ and LR- were modest.

This article is protected by copyright. All rights reserved. 
Combining the pre-exercise systolic BP and post-exercise systolic BPs (both pre-exercise systolic BP and post-exercise systolic BP above respective thresholds), increased net specificity, PPV and LR+ from that of the individual pre-exercise and post-exercise BPs. Similarly, when pre-exercise and recovery-exercise systolic BP (both pre-exercise and recovery-exercise systolic BP above thresholds), or post-exercise and recovery-exercise systolic BP (both post-exercise and recovery-exercise systolic BP above thresholds) were combined, the specificity, PPV and LR+ were marginally higher than for individual BP, but sensitivity was low. When all three BP measures were combined (pre-exercise, post-exercise and recovery-exercise systolic BP above thresholds), the specificity, PPV and LR+ were increased, but sensitivity remained low (table 3).

Generalized linear models for predictors of masked hypertension were constructed with clinic, pre-exercise, post-exercise or recovery-exercise systolic BP, sex, age and BMI entered as independent variables. As shown in supplementary table 2, each $10 \mathrm{mmHg}$ of clinic systolic BP was associated with masked hypertension independent of sex, age and BMI. Similarly, each $10 \mathrm{mmHg}$ of pre-exercise, post-exercise and recovery-exercise systolic BP was associated with masked hypertension independent of sex, age and BMI, although these associations became non-significant following further adjustment for clinic systolic BP. Within each of the models containing the pre-exercise, post-exercise or recovery-exercise systolic BP, the clinic systolic BP remained an independent predictor of masked hypertension.

Those classified with masked hypertension had higher LV mass index compared to those classified with normal BP (table 1). Using the same thresholds of pre-exercise, post-exercise and recovery-exercise systolic BP that were associated with masked hypertension, LV mass index and aortic PWV were higher in those with systolic BP above respective thresholds (when derived with Youden's criteria) compared to those with systolic BP below (figure 2). Results were broadly similar using thresholds based on the minimal difference criteria. As 
shown in supplementary table 3, differences in LV mass index and aortic PWV between individuals above and below the thresholds were attenuated (but remained significant) after adjustment for age, sex and BMI. All differences became non-significant following additional adjustment for clinic BP, with the exception of LV mass index and the recovery-exercise BP threshold.

\section{Discussion}

This investigation sought to determine whether elevated exercise BP could identify or rule out the presence of masked hypertension in adolescents. The principal finding was that systolic BP following a submaximal exercise step-test is associated with the presence of masked hypertension with low sensitivity, but high specificity. The same thresholds of exercise BP that were associated with masked hypertension were also associated with increased aortic stiffness and LV mass index, although largely attenuated with adjustment for clinic BP. Taken together, measurement of exercise BP in adolescence may be a useful additional screening tool to clinic BP for ruling out high BP and cardiovascular risk.

In adults habitual BP is optimally assessed via measurement of BP using out-of-clinic methods, the gold standard of which is 24 -hour ambulatory BP monitoring. ${ }^{2}$ This is because it is more strongly associated with adverse cardiovascular outcomes, ${ }^{4}$ and also because it provides a more reliable estimate of the BP load encountered during daily life. Dynamic exercise of a light-to-moderate or 'submaximal' intensity reflects a cardiovascular load commensurate with activities of daily living. Thus, measurement of BP during submaximal exercise may more closely reflect BP load not captured via in-clinic measures, and without the requirement for out-of-clinic assessment. In adulthood, elevated systolic BP during or immediately following exercise is associated with increased risk of developing 
hypertension, ${ }^{25,26}$ cardiovascular events and mortality. ${ }^{27}$ Importantly, masked hypertension may underlie the increased risk associated with high exercise BP (specifically when recorded at submaximal intensities). ${ }^{9,}{ }^{28}$ The current study, using a large representative sample of adolescents in the United Kingdom population, is the first to show that systolic BP measured prior, post and in recovery from a submaximal exercise is useful in ruling out masked hypertension in young people.

Several thresholds of exercise systolic BP (pre-, post- or recovery-exercise systolic BP) were explored to assess the optimal cut-point to identify masked hypertension using the minimal difference criteria. Whilst no threshold could be labelled as optimal, all exercise BP thresholds showed similar sensitivity and specificity values. It should however be noted that the prevalence of masked hypertension within our study sample was low $(7.8 \%)$, which is consistent with reports from other adolescent populations. ${ }^{8,15}$ This low prevalence explains the relatively low positive predictive values observed. Combining two or more thresholds also only marginally increased positive predictive value and $\mathrm{LR}+$ to identify masked hypertension by comparison to that of the individual thresholds. Although this suggests systolic BP responses to step-exercise testing are not definitive in terms of 'diagnosing' masked hypertension (which should be confirmed with out-of-clinic BP monitoring in any case), the high negative predicative values indicate that the presence of masked hypertension can be effectively ruled out by exercise testing. This result carries a level of clinical relevance, since those with masked hypertension have at least similar, ${ }^{4}$ if not greater, ${ }^{29}$ cardiovascular disease mortality risk than those diagnosed with sustained hypertension. Individuals found to have normal BP in the clinic have no indication for out-of-clinic BP monitoring and the presence of masked hypertension may be overlooked, with the associated cardiovascular risk missed. Although clinic BP provided predictive value for discriminating masked hypertension from normal BP (with high sensitivity), the identified systolic BP thresholds 
(115 and $120 \mathrm{mmHg}$ ) were low, meaning many individuals may, in theory, be sent for ambulatory monitoring. In this instance, the exercise BP response may provide some additional reassurance of truly 'normal' BP without the need for extensive out-of-clinic monitoring. However, it should be stressed that the information gained from exercise BP is complementary to clinic BP only, not superior.

The detection of high BP in childhood and adolescence is important, since high BP in childhood and adolescence tracks through to adulthood, ${ }^{30,31}$ increasing propensity for an adverse cardiovascular risk profile. Indeed, previous research has shown that those identified with masked hypertension in adolescence are at increased risk of developing sustained hypertension and left ventricular hypertrophy later in life. ${ }^{8,15,32}$ In a large sample of prehypertensive adults, Kokkinos et al found that each $10 \mathrm{mmHg}$ elevation in systolic BP above a threshold of $150 \mathrm{mmHg}$ during submaximal exercise (Bruce treadmill stage 2) was associated with a 4-fold increased risk of LV hypertrophy. ${ }^{33}$ The same submaximal exercise systolic BP threshold of $150 \mathrm{mmHg}$ was also associated with underlying hypertension confirmed by 24-hour ambulatory monitoring in an older clinical population undergoing diagnostic exercise stress testing. ${ }^{11}$ Our previous study involving this 17 -year-old sample from the ALSPAC indicated post-exercise and recovery-exercise BP to be associated with markers of cardiovascular risk, including raised LV mass index and aortic stiffness. Thus, it is interesting to note that the exercise systolic BP thresholds associated with masked hypertension in this 17-year-old adolescent cohort were also associated with raised aortic stiffness and LV mass index. This further highlights the potential usefulness of exercise BP in cardiovascular risk prediction in adolescence.

This article is protected by copyright. All rights reserved. 
There are some limitations to our study. The ALSPAC cohort is predominantly white European, and thus the results may not extrapolate to other ethnic groups. Due to non-fixed sleep and wake times, the percentage of daytime and night-time readings contributing to classification of masked hypertension may differ for each individual, and thus could have led to over- or under-estimation of true masked hypertension prevalence. The analysis was crosssectional, and further longitudinal studies are required to confirm if raised exercise BP in adolescence predicts development of hypertension and increased cardiovascular risk in adulthood.

\section{Perspectives.}

Masked hypertension is associated with elevated cardiovascular disease risk but is largely undetectable from clinic BP alone. Our results demonstrate that BP measured in response to a simple, readily implemented submaximal exercise step test rules out masked hypertension, suggesting this form of exercise testing as a useful addition to clinic BP to rule out BP-related cardiovascular risk in adolescence.

\section{Acknowledgments.}

We are extremely grateful to all the families who took part in this study, the midwives for their help in recruiting them, and the whole ALSPAC team, which includes interviewers, computer and laboratory technicians, clerical workers, research scientists, volunteers, managers, receptionists and nurses. This publication is the work of the authors and the corresponding author will serve as guarantor for the contents of this paper. The UK Medical Research Council and Wellcome (Grant ref: 102215/2/13/2) and the University of Bristol provide core support for ALSPAC. A comprehensive list of grants funding is available on the 
ALSPAC website. This study was specifically funded by grants to ADH from the British Heart Foundation (PG/06/145 \& CS/15/6/31468) and Wellcome Trust (086676/Z/08/Z). MGS is supported by a National Health and Medical Research Council Australia Early Career Fellowship (reference 1104731). LDH, GDS and DAL work in a Unit that receives support from the University of Bristol and UK Medical Research Council (MC_UU_12013/1 and MC_UU_12013/5). LDH is funded by a Career Development Award from the UK Medical Research Council (MR/M020894/1). ADH and NC received support from the National Institute for Health Research University College London Hospitals Biomedical Research Centre.

\section{Figure Legends}

Figure 1. Participant flow for this study. PWV: aortic pulse wave velocity; LVMI: left ventricular (LV) mass index.

Figure 2. Left ventricular (LV) mass index and aortic pulse wave velocity (PWV) between those with a) pre-exercise systolic $\mathrm{BP}<$ or $\geq 126 \mathrm{mmHg}$; b) post-exercise systolic $\mathrm{BP}<$ or $\geq$ $150 \mathrm{mmHg}$; and c) recovery-exercise systolic $\mathrm{BP}<$ or $\geq 130 \mathrm{mmHg}$. Data presented as means \pm standard error. $p$ value is for between group analyses.

This article is protected by copyright. All rights reserved. 


\section{References}

1. Lewington S, Clarke R, Qizilbash N, Peto R and Collins R. Age-specific relevance of usual blood pressure to vascular mortality: a meta-analysis of individual data for one million adults in 61 prospective studies. Lancet. 2002;360:1903-13.

2. Mancia G, Fagard R, Narkiewicz K, Redon J, Zanchetti A, Bohm M, Christiaens T, Cifkova R, De Backer G, Dominiczak A, Galderisi M, Grobbee DE, Jaarsma T, Kirchhof P, Kjeldsen SE, Laurent S, Manolis AJ, Nilsson PM, Ruilope LM, Schmieder RE, Sirnes PA, Sleight P, Viigimaa M, Waeber B, Zannad F, Redon J, Dominiczak A, Narkiewicz K, Nilsson PM, Burnier M, Viigimaa M, Ambrosioni E, Caufield M, Coca A, Olsen MH, Schmieder RE, Tsioufis C, van de Borne P, Zamorano JL, Achenbach S, Baumgartner H, Bax JJ, Bueno H, Dean V, Deaton C, Erol C, Fagard R, Ferrari R, Hasdai D, Hoes AW, Kirchhof P, Knuuti J, Kolh P, Lancellotti P, Linhart A, Nihoyannopoulos P, Piepoli MF, Ponikowski P, Sirnes PA, Tamargo JL, Tendera M, Torbicki A, Wijns W, Windecker S, Clement DL, Coca A, Gillebert TC, Tendera M, Rosei EA, Ambrosioni E, Anker SD, Bauersachs J, Hitij JB, Caulfield M, De Buyzere M, De Geest S, Derumeaux GA, Erdine S, Farsang C, Funck-Brentano C, Gerc V, Germano G, Gielen S, Haller H, Hoes AW, Jordan J, Kahan T, Komajda M, Lovic D, Mahrholdt H, Olsen MH, Ostergren J, Parati G, Perk J, Polonia J, Popescu BA, Reiner Z, Ryden L, Sirenko Y, Stanton A, Struijker-Boudier H, Tsioufis C, van de Borne P, Vlachopoulos C, Volpe M and Wood DA. 2013 ESH/ESC guidelines for the management of arterial hypertension: the Task Force for the Management of Arterial Hypertension of the European Society of Hypertension (ESH) and of the European Society of Cardiology (ESC). Eur Heart J. 2013;34:2159-219.

3. James PA, Oparil S, Carter BL, Cushman WC, Dennison-Himmelfarb C, Handler J, Lackland DT, LeFevre ML, MacKenzie TD, Ogedegbe O, Smith SC, Jr., Svetkey LP, Taler SJ, Townsend RR, Wright JT, Jr., Narva AS and Ortiz E. 2014 evidence-based guideline for 
the management of high blood pressure in adults: report from the panel members appointed to the Eighth Joint National Committee (JNC 8). JAMA. 2014;311:507-20.

4. Mancia G, Facchetti R, Bombelli M, Grassi G and Sega R. Long-term risk of mortality associated with selective and combined elevation in office, home, and ambulatory blood pressure. Hypertension. 2006;47:846-53.

5. Mancia G, Bombelli M, Facchetti R, Madotto F, Quarti-Trevano F, Polo Friz H, Grassi G and Sega R. Long-term risk of sustained hypertension in white-coat or masked hypertension. Hypertension. 2009;54:226-32.

6. Sega R, Trocino G, Lanzarotti A, Carugo S, Cesana G, Schiavina R, Valagussa F, Bombelli M, Giannattasio C, Zanchetti A and Mancia G. Alterations of cardiac structure in patients with isolated office, ambulatory, or home hypertension: Data from the general population (Pressione Arteriose Monitorate E Loro Associazioni [PAMELA] Study). Circulation. 2001;104:1385-92.

7. Bjorklund K, Lind L, Zethelius B, Andren B and Lithell H. Isolated ambulatory hypertension predicts cardiovascular morbidity in elderly men. Circulation. 2003;107:1297302.

8. Lurbe E, Torro I, Alvarez V, Nawrot T, Paya R, Redon J and Staessen JA. Prevalence, persistence, and clinical significance of masked hypertension in youth. Hypertension. 2005;45:493-8.

9. Schultz MG, Hare JL, Marwick TH, Stowasser M and Sharman JE. Masked hypertension is "unmasked" by low-intensity exercise blood pressure. Blood Press. 2011;20:284-9.

10. Stergiou GS, Rarra VC and Yiannes NG. Prevalence and predictors of masked hypertension detected by home blood pressure monitoring in children and adolescents: the Arsakeion School study. Am J Hypertens. 2009;22:520-4.

This article is protected by copyright. All rights reserved. 
11. Schultz MG, Picone DS, Nikolic SB, Williams AD and Sharman JE. Exaggerated blood pressure response to early stages of exercise stress testing and presence of hypertension. J Sci Med Sport. 2016;19:1039-1042.

12. Boyd A, Golding J, Macleod J, Lawlor DA, Fraser A, Henderson J, Molloy L, Ness A, Ring S and Davey Smith G. Cohort profile: the 'children of the 90s'-the index offspring of the Avon Longitudinal Study of Parents and Children. International journal of epidemiology. 2013;42:111-127.

13. Fraser A, Macdonald-Wallis C, Tilling K, Boyd A, Golding J, Davey Smith G, Henderson J, Macleod J, Molloy L and Ness A. Cohort profile: the Avon Longitudinal Study of Parents and Children: ALSPAC mothers cohort. International journal of epidemiology. 2012;42:97-110.

14. Hughes $\mathrm{AD}$ and Chaturvedi N. Estimation of Maximal Oxygen Consumption and Heart Rate Recovery Using the Tecumseh Sub-Maximal Step Test and their Relationship to Cardiovascular Risk Factors. Artery Res. 2017;18:29-35.

15. Lurbe E, Agabiti-Rosei E, Cruickshank JK, Dominiczak A, Erdine S, Hirth A, Invitti C, Litwin M, Mancia G, Pall D, Rascher W, Redon J, Schaefer F, Seeman T, Sinha M, Stabouli S, Webb NJ, Wuhl E and Zanchetti A. 2016 European Society of Hypertension guidelines for the management of high blood pressure in children and adolescents. $J$ Hypertens. 2016;34:1887-920.

16. Verdecchia P, Angeli F, Sardone M, Borgioni C, Garofoli M and Reboldi G. Is the definition of daytime and nighttime blood pressure prognostically relevant? Blood pressure monitoring. 2008;13:153-155.

17. Bromfield SG, Booth JN, Loop MS, Schwartz JE, Seals SR, Thomas SJ, Min Y-I, Ogedegbe G, Shimbo D and Muntner P. Evaluating different criteria for defining a complete 
ambulatory blood pressure monitoring recording: data from the Jackson Heart Study. Blood pressure monitoring. 2018;23:103-111.

18. O'brien E, Beevers G and Lip GY. Blood pressure measurement: Part IIIAutomated sphygmomanometry: ambulatory blood pressure measurement. Bmj. 2001;322:1110-1114.

19. Mezick EJ, Hall M and Matthews KA. Sleep duration and ambulatory blood pressure in black and white adolescents. Hypertension. 2012:HYPERTENSIONAHA. 111.184770.

20. Lang RM, Bierig M, Devereux RB, Flachskampf FA, Foster E, Pellikka PA, Picard MH, Roman MJ, Seward J, Shanewise JS, Solomon SD, Spencer KT, Sutton MS and Stewart WJ. Recommendations for chamber quantification: a report from the American Society of Echocardiography's Guidelines and Standards Committee and the Chamber Quantification Writing Group, developed in conjunction with the European Association of Echocardiography, a branch of the European Society of Cardiology. J Am Soc Echocardiogr. 2005;18:1440-63.

21. Laurent S, Cockcroft J, Van Bortel L, Boutouyrie P, Giannattasio C, Hayoz D, Pannier B, Vlachopoulos C, Wilkinson I and Struijker-Boudier H. Expert consensus document on arterial stiffness: methodological issues and clinical applications. Eur Heart J. 2006;27:2588-605.

22. Tamhane AR, Westfall AO, Burkholder GA and Cutter GR. Prevalence odds ratio versus prevalence ratio: choice comes with consequences. Statistics in medicine. 2016;35:5730-5735.

23. Barros AJ and Hirakata VN. Alternatives for logistic regression in cross-sectional studies: an empirical comparison of models that directly estimate the prevalence ratio. $B M C$ medical research methodology. 2003;3:21.

24. Martinez BAF, Leotti VB, Nunes LN, Machado G and Corbellini LG. Odds Ratio or Prevalence Ratio? An Overview of Reported Statistical Methods and Appropriateness of 
Interpretations in Cross-sectional Studies with Dichotomous Outcomes in Veterinary Medicine. Frontiers in veterinary science. 2017;4:193.

25. Schultz MG, Otahal P, Picone DS and Sharman JE. Clinical Relevance of Exaggerated Exercise Blood Pressure. J Am Coll Cardiol. 2015;66:1843-1845.

26. Manolio TA, Burke GL, Savage PJ, Sidney S, Gardin JM and Oberman A. Exercise blood pressure response and 5-year risk of elevated blood pressure in a cohort of young adults: the CARDIA study. Am J Hypertens. 1994;7:234-41.

27. Schultz MG, Otahal P, Cleland VJ, Blizzard L, Marwick TH and Sharman JE. Exercise-induced hypertension, cardiovascular events, and mortality in patients undergoing exercise stress testing: a systematic review and meta-analysis. Am J Hypertens. 2013;26:35766.

28. Kayrak M, Bacaksiz A, Vatankulu MA, Ayhan SS, Kaya Z, Ari H, Sonmez O and Gok H. Exaggerated blood pressure response to exercise--a new portent of masked hypertension. Clin Exp Hypertens. 2010;32:560-8.

29. Banegas JR, Ruilope LM, de la Sierra A, Vinyoles E, Gorostidi M, de la Cruz JJ, Ruiz-Hurtado G, Segura J, Rodriguez-Artalejo F and Williams B. Relationship between Clinic and Ambulatory Blood-Pressure Measurements and Mortality. The New England journal of medicine. 2018;378:1509-1520.

30. Theodore RF, Broadbent J, Nagin D, Ambler A, Hogan S, Ramrakha S, Cutfield W, Williams MJ, Harrington H, Moffitt TE, Caspi A, Milne B and Poulton R. Childhood to Early-Midlife Systolic Blood Pressure Trajectories: Early-Life Predictors, Effect Modifiers, and Adult Cardiovascular Outcomes. Hypertension. 2015;66:1108-15.

31. Chen X and Wang Y. Tracking of blood pressure from childhood to adulthood: a systematic review and meta-regression analysis. Circulation. 2008;117:3171-80.

This article is protected by copyright. All rights reserved. 
32. Lurbe E, Thijs L, Torro MI, Alvarez J, Staessen JA and Redon J. Sexual dimorphism in the transition from masked to sustained hypertension in healthy youths. Hypertension. $2013 ; 62: 410-4$.

33. Kokkinos P, Pittaras A, Narayan P, Faselis C, Singh S and Manolis A. Exercise capacity and blood pressure associations with left ventricular mass in prehypertensive individuals. Hypertension. 2007;49:55-61.

This article is protected by copyright. All rights reserved. 
Table 1. Demographic and clinical characteristics by blood pressure classification.

\begin{tabular}{|c|c|c|c|c|}
\hline & All & Normal BP & $\begin{array}{l}\text { Masked } \\
\text { hypertension }\end{array}$ & $\begin{array}{l}P \\
\text { value }^{\wedge}\end{array}$ \\
\hline \multicolumn{5}{|c|}{ a. Clinical/demographic information } \\
\hline Age, years $(n=635)$ & $17.71 \pm 0.33$ & $17.71 \pm 0.33$ & $17.64 \pm 0.35$ & 0.182 \\
\hline male $\operatorname{sex}^{\$}(n=638)$ & $255(40.0)$ & $231(39.3)$ & $24(48.0)$ & 0.227 \\
\hline Height, $\mathrm{cm}(\mathrm{n}=627)$ & $170.15 \pm 9.34$ & $170.05 \pm 9.36$ & $171.31 \pm 9.07$ & 0.360 \\
\hline Weight, $\mathrm{kg}(\mathrm{n}=628)$ & $66.33 \pm 12.62$ & $65.93 \pm 12.31$ & $70.91 \pm 15.07$ & 0.007 \\
\hline BMI, kg/m² (n=627) & $22.89 \pm 3.91$ & $22.79 \pm 3.85$ & $24.10 \pm 4.35$ & 0.022 \\
\hline \multicolumn{5}{|l|}{ b. $\quad$ Blood Biochemistry } \\
\hline Total cholesterol, $\mathrm{mmol} / \mathrm{L}(\mathrm{n}=454)$ & $3.69 \pm 0.66$ & $3.67 \pm 0.65$ & $3.92 \pm 0.74$ & 0.033 \\
\hline HDL cholesterol, $\mathrm{mmol} / \mathrm{L}(\mathrm{n}=454)$ & $1.27 \pm 0.28$ & $1.27 \pm 0.28$ & $1.22 \pm 0.33$ & 0.287 \\
\hline Triglycerides, $\mathrm{mmol} / \mathrm{L}(\mathrm{n}=454)$ & $0.80 \pm 0.33$ & $0.78 \pm 0.31$ & $1.00 \pm 0.46$ & $<0.001$ \\
\hline Glucose, $\mathrm{mmol} / \mathrm{L}(\mathrm{n}=441)$ & $4.17 \pm 0.37$ & $4.16 \pm 0.37$ & $4.21 \pm 0.29$ & 0.457 \\
\hline Haemoglobin, mmol/L ( $\mathrm{n}=453)$ & $138.4 \pm 13.9$ & $138.2 \pm 13.9$ & $140.8 \pm 13.1$ & 0.302 \\
\hline \multicolumn{5}{|l|}{ c. $\quad$ Cardiovascular risk markers } \\
\hline LV mass index, $\mathrm{g} / \mathrm{m}^{2.7}(\mathrm{n}=550)$ & $28.33 \pm 6.03$ & $28.12 \pm 5.97$ & $30.91 \pm 6.12$ & 0.003 \\
\hline Aortic PWV, m/s (n=524) & $5.77 \pm 0.71$ & $5.75 \pm 0.72$ & $5.91 \pm 0.57$ & 0.211 \\
\hline
\end{tabular}

BMI: body mass index. HDL: high-density lipoprotein. LDL: low-density lipoprotein. LV mass index: left ventricular mass index. Data are presented as mean \pm SD or $\mathrm{n}(\%) .{ }^{\$}$ male sex represents the $\mathrm{n}(\%)$ of males in the two blood pressure categories. ${ }^{\wedge} p$ value comparing the two blood pressure categories by t-test; or chi-square tests for categorical variables.

This article is protected by copyright. All rights reserved. 
Table 2. Clinic BP, 24-hour ambulatory and exercise test parameters.

\begin{tabular}{|c|c|c|c|c|}
\hline & All & $\begin{array}{l}\text { Normal BP } \\
(n=588)\end{array}$ & $\begin{array}{l}\text { Masked } \\
\text { hypertension } \\
(\mathbf{n = 5 0})\end{array}$ & $p$ value \\
\hline \multicolumn{5}{|l|}{ a. $\quad$ Clinic (resting) $B P$} \\
\hline Clinic SBP, mmHg & $115 \pm 10$ & $115 \pm 10$ & $126 \pm 8$ & $<0.001$ \\
\hline Clinic DBP, mmHg & $64 \pm 7$ & $64 \pm 7$ & $69 \pm 8$ & $<0.001$ \\
\hline \multicolumn{5}{|l|}{ b. $\quad$ 24-hour ambulatory $B P$} \\
\hline Daytime SBP, mmHg & $124 \pm 9$ & $123 \pm 8$ & $141 \pm 6$ & $<0.001$ \\
\hline Daytime DBP, mmHg & $73 \pm 6$ & $73 \pm 5$ & $81 \pm 5$ & $<0.001$ \\
\hline Night time SBP, mmHg & $107 \pm 9$ & $106 \pm 8$ & $120 \pm 8$ & $<0.001$ \\
\hline Night time DBP, mmHg & $58 \pm 6$ & $58 \pm 5$ & $64 \pm 7$ & $<0.001$ \\
\hline 24-hour SBP, mmHg & $118 \pm 8$ & $116 \pm 7$ & $133 \pm 4$ & $<0.001$ \\
\hline 24-hour DBP, mmHg & $68 \pm 5$ & $67 \pm 5$ & $75 \pm 5$ & $<0.001$ \\
\hline Nocturnal dipping SBP, \% & $14 \pm 6$ & $14 \pm 6$ & $15 \pm 7$ & 0.347 \\
\hline Nocturnal dipping DBP, \% & $21 \pm 7$ & $20 \pm 7$ & $21 \pm 8$ & 0.520 \\
\hline 24-hour SBP load, \% & $45 \pm 25$ & $42 \pm 23$ & $81 \pm 9$ & $<0.001$ \\
\hline 24-hour DBP load, \% & $17 \pm 16$ & $16 \pm 14$ & $40 \pm 19$ & $<0.001$ \\
\hline Daytime SBP load, \% & $56 \pm 30$ & $53 \pm 29$ & $92 \pm 11$ & $<0.001$ \\
\hline Daytime DBP load, \% & $22 \pm 20$ & $20 \pm 18$ & $50 \pm 22$ & $<0.001$ \\
\hline Night time SBP load, \% & $14 \pm 20$ & $11 \pm 16$ & $50 \pm 26$ & $<0.001$ \\
\hline Night time DBP load, \% & $4 \pm 11$ & $3 \pm 10$ & $12 \pm 22$ & $<0.001$ \\
\hline \multicolumn{5}{|l|}{ c. $\quad$ Exercise Test Parameters } \\
\hline Pre-exercise SBP, mmHg & $120 \pm 12$ & $119 \pm 12$ & $129 \pm 13$ & $<0.001$ \\
\hline Pre-exercise DBP, mmHg & $74 \pm 8$ & $73 \pm 8$ & $79 \pm 9$ & $<0.001$ \\
\hline Pre-exercise HR, bpm & $82 \pm 12$ & $82 \pm 12$ & $81 \pm 11$ & 0.609 \\
\hline Post-exercise SBP, mm Hg & $142 \pm 16$ & $141 \pm 15$ & $153 \pm 18$ & $<0.001$ \\
\hline Post-exercise DBP, $\mathrm{mmHg}$ & $82 \pm 12$ & $80 \pm 10$ & $84 \pm 12$ & 0.003 \\
\hline Post-exercise HR, bpm & $106 \pm 22$ & $106 \pm 22$ & $104 \pm 18$ & 0.477 \\
\hline Recovery-exercise SBP, mmHg & $127 \pm 12$ & $126 \pm 12$ & $137 \pm 13$ & $<0.001$ \\
\hline Recovery-exercise DBP, mmHg & $81 \pm 9$ & $80 \pm 8$ & $87 \pm 9$ & $<0.001$ \\
\hline Recovery-exercise, HR, bpm & $89 \pm 15$ & $89 \pm 15$ & $90 \pm 14$ & 0.566 \\
\hline Pre-post SBP change, $\mathrm{mmHg}$ & $23 \pm 13$ & $22 \pm 13$ & $24 \pm 15$ & 0.569 \\
\hline $\begin{array}{l}\text { Post-recovery SBP change, } \\
\mathrm{mmHg}\end{array}$ & $-15 \pm 12$ & $-15 \pm 12$ & $-16 \pm 12$ & 0.826 \\
\hline
\end{tabular}

Data are as mean $\pm \mathrm{SD} ;^{\wedge} p$ value comparing the two blood pressure categories by t-test. SBP, systolic blood pressure; DBP, diastolic blood pressure; HR, heart rate.

This article is protected by copyright. All rights reserved. 
Table 3. Exercise blood pressure in revealing masked hypertension.

\begin{tabular}{|c|c|c|c|c|c|c|c|c|}
\hline & Threshold & $\begin{array}{l}\text { Positive } \\
\text { test } \\
\text { result } \\
\text { (n) }\end{array}$ & Sensitivity & Specificity & $\begin{array}{l}\text { Positive } \\
\text { predictive } \\
\text { value }\end{array}$ & $\begin{array}{l}\text { Negative } \\
\text { predictive } \\
\text { value }\end{array}$ & $\begin{array}{l}\text { Positive } \\
\text { likelihood } \\
\text { ratio }\end{array}$ & $\begin{array}{l}\text { Negative } \\
\text { likelihood } \\
\text { ratio }\end{array}$ \\
\hline \multirow{7}{*}{$\begin{array}{l}\text { Youden's } \\
\text { index }\end{array}$} & Clinic (resting) systolic BP $115 \mathrm{mmHg}$ & 317 & $94.0 \%$ & $53.5 \%$ & $14.8 \%$ & $99.0 \%$ & 2.0 & 0.1 \\
\hline & Pre-exercise systolic BP 126 mmHg & 195 & $70.0 \%$ & $72.3 \%$ & $17.9 \%$ & $96.5 \%$ & 2.5 & 0.4 \\
\hline & Post-exercise systolic BP $150 \mathrm{mmHg}$ & 186 & $56.0 \%$ & $72.8 \%$ & $15.1 \%$ & $95.1 \%$ & 2.1 & 0.6 \\
\hline & Recovery-exercise systolic BP $130 \mathrm{mmHg}$ & 250 & $76.0 \%$ & $63.5 \%$ & $15.2 \%$ & $96.9 \%$ & 2.1 & 0.4 \\
\hline & $\begin{array}{l}\text { Pre-exercise systolic BP } 126 \mathrm{mmHg} \& \text { post-exercise } \\
\text { systolic BP } 150 \mathrm{mmHg}\end{array}$ & 119 & $52.0 \%$ & $84.0 \%$ & $21.8 \%$ & $95.3 \%$ & 3.3 & 0.6 \\
\hline & $\begin{array}{l}\text { Pre-exercise systolic BP } 126 \mathrm{mmHg} \& \text { recovery- } \\
\text { exercise systolic BP } 130 \mathrm{mmHg}\end{array}$ & 155 & $62.0 \%$ & $78.7 \%$ & $20.0 \%$ & $96.0 \%$ & 2.9 & 0.5 \\
\hline & $\begin{array}{l}\text { Pre-exercise systolic BP } 126 \mathrm{mmHg} \text {, post-exercise } \\
\text { systolic BP } 150 \mathrm{mmHg} \& \text { recovery-exercise systolic BP } \\
130 \mathrm{mmHg}\end{array}$ & 102 & $52.0 \%$ & $86.9 \%$ & $25.5 \%$ & $95.5 \%$ & 4.0 & 0.6 \\
\hline \multirow{2}{*}{$\begin{array}{l}\text { Minimal } \\
\text { difference }\end{array}$} & Clinic (resting) systolic BP $120 \mathrm{mmHg}$ & 207 & $70.0 \%$ & $70.4 \%$ & $16.9 \%$ & $96.5 \%$ & 2.4 & 0.4 \\
\hline & Pre-exercise systolic BP $125 \mathrm{mmHg}$ & 204 & $70.0 \%$ & $70.9 \%$ & $17.2 \%$ & $96.5 \%$ & 2.4 & 0.4 \\
\hline
\end{tabular}

This article is protected by copyright. All rights reserved. 
Post-exercise systolic BP $146 \mathrm{mmHg}$

Recovery-exercise systolic BP $132 \mathrm{mmHg}$

Pre-exercise systolic BP $125 \mathrm{mmHg} \&$ post-exercise systolic BP $146 \mathrm{mmHg}$

Pre-exercise systolic BP $125 \mathrm{mmHg} \&$ recoveryexercise systolic BP $132 \mathrm{mmHg}$

Post-exercise systolic BP $146 \mathrm{mmHg} \&$ recoveryexercise systolic BP $132 \mathrm{mmHg}$

Pre-exercise systolic BP $125 \mathrm{mmHg}$, post-exercise systolic BP $146 \mathrm{mmHg} \&$ recovery-exercise systolic BP $132 \mathrm{mmHg}$ 


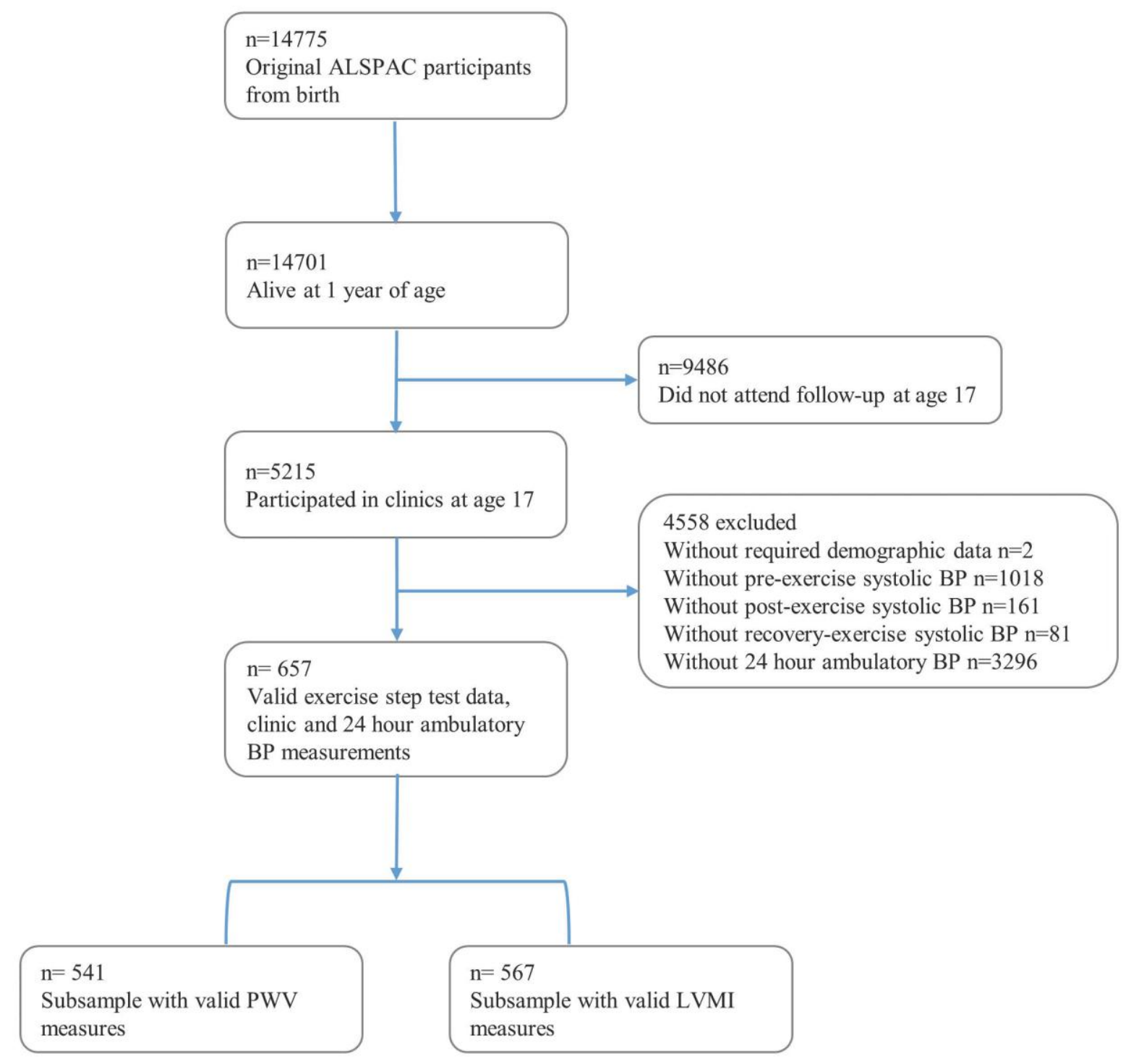

This article is protected by copyright. All rights reserved. 

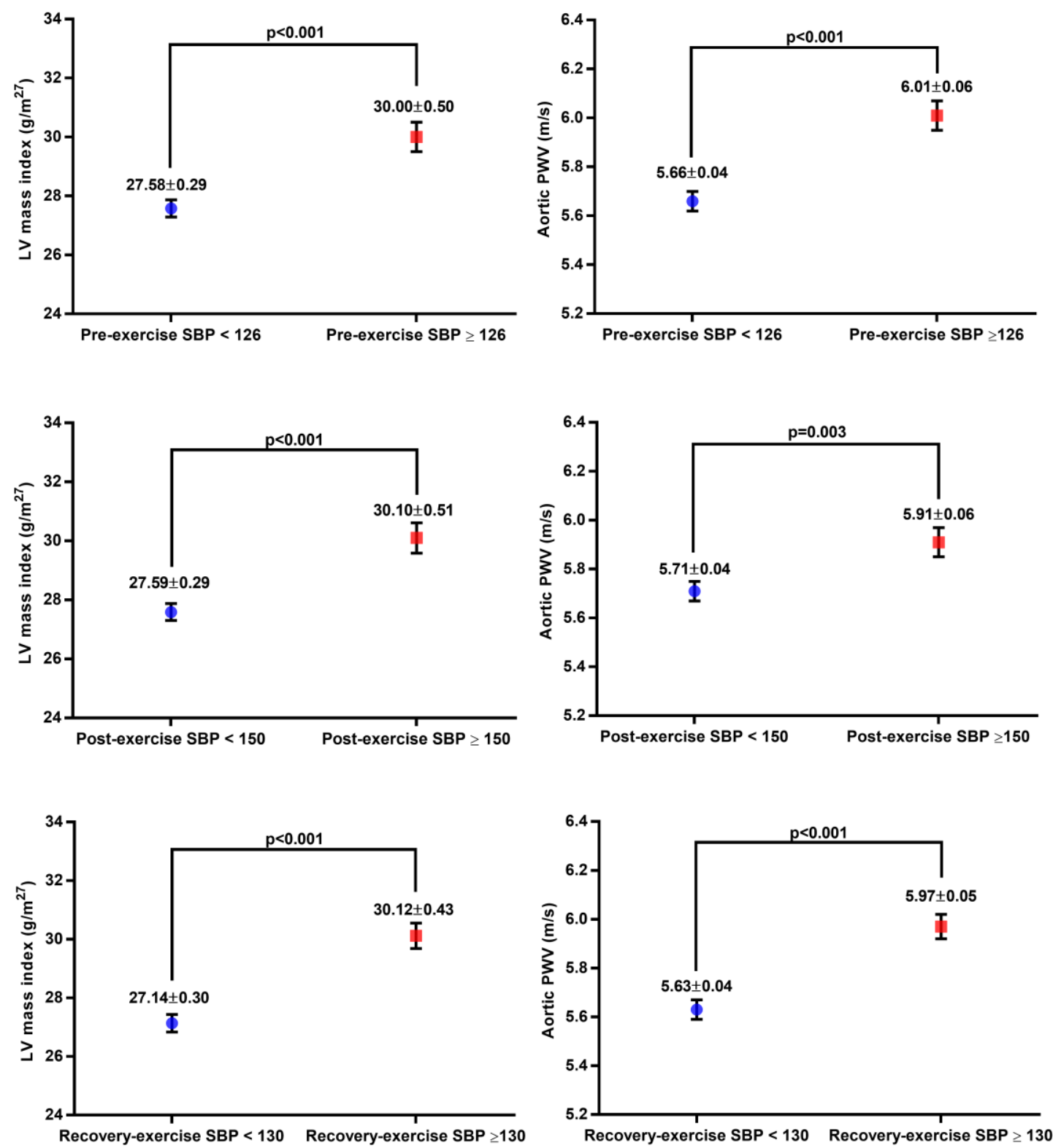

This article is protected by copyright. All rights reserved. 